\title{
A formação de professoras na Escola Normal Nossa Senhora da Piedade (1919 a 1925)
}

\author{
Teacher training of Escola Normal Nossa Senhora da
}

Piedade (1919 to 1925)

Formación de profesores en la Escuela Normal Nossa

Senhora da Piedade (1919 hasta1925)

MARTHA RaÍsSA IANE SANTANA DA SILVA ia

LARISSA PINCA SARRO GOMES (iD

\section{Resumo}

No ano de 1919 foi solicitado ao governador da Bahia autorização para o funcionamento da Escola Normal Nossa Senhora da Piedade, na cidade de Ilhéus, região sul da Bahia. A investigação das contribuições dessa instituição é significativa pois se trata de um período no qual, a duras penas, se investia no processo de interiorização de instituições que oferecessem mão-de-obra suficiente para a propagação do ensino primário. Esse fato se observava não apenas no estado da Bahia, como em todo o Brasil. Neste artigo, interroga-se, especificamente, a respeito dos saberes ofertados na escola normal da instituição, de inspiração francesa. Os resultados apresentados abrangem um marco temporal de 1919 a 1925, considerando como início o ano em que foi concedida a autorização para o funcionamento dessa instituição escolar, e a data final corresponde ao limite de registros de reportagens localizadas no Jornal Correio de Ilhéos - entre os anos de 1920 a 1925. A partir de uma aproximação teórica com autores da História Cultural e com autores que discutem a organização dos saberes de formação foi possível destacar elementos da cultura escolar, da organização e do currículo dessa instituição, a qual ofertava disciplinas de cunho

\footnotetext{
${ }^{a}$ Universidade Federal de São Paulo (UNIFESP), São Paulo, SP, Brasil. Doutora em Ciências, e-mail: martharaissa@hotmail.com

b Universidade Estadual de Santa Cruz (UESC), Ilhéus, BA, Brasil. Doutora em Educação, e-mail: Ipsgomes@uesc.br
} 
pedagógico, ao longo de toda a formação. Tal constatação ganha destaque, em tempos da predominância de disciplinas de cultura geral, "científicas", nos currículos das escolas normais do Brasil, relegando as disciplinas pedagógicas ao último ano da formação. As disciplinas "científicas", entretanto, continuavam a ter primazia no currículo a saber: Mathemáticas, Português, História, Geografia etc. Disciplinas como Pedagogia e Metodologia, compondo o conjunto de saberes profissionais, têm seu lugar no currículo da instituição, permitindo concluir quanto à existência de duas naturezas distintas, em termos de formação de professores, uma de cultura geral e outra de formação profissional.

Palavras-chave: Escola Normal. Formação de professores. Cultura escolar. Saberes profissionais.

\section{Abstract}

In 1919, the Governor of Bahia was asked for authorization to operate the Escola Normal Nossa Senhora da Piedade, in the city of Ilhéus, southern Bahia. The investigation of the contributions of this institution is significant, as it is a period in which, the hard way, investments were made in the process of internalizing institutions that offered sufficient labor for the spread of primary education. This fact was observed not only in the state of Bahia, but throughout Brazil. In this article, he specifically asks about the knowledge offered in the institution's normal school, of French inspiration. The presented results cover a time frame from 1919 to 1925, considering the beginning of the year in which authorization to operate was granted about this school institution, and the final date corresponds to the reporting located in Jornal Correio de Ilhéos - between the years 1920 to 1925. From a theoretical approach with authors of Cultural History and with authors who discuss the organization of training knowledge it was possible to highlight elements of the school culture, organization and curriculum of this institution, which offered disciplines of a pedagogical nature, throughout the training. This finding is highlighted, in times of the predominance of disciplines of general culture, "scientific", in the curricula of normal schools in Brazil, relegating pedagogical subjects to the last year of training. The "scientific" disciplines, however, continued to have primacy in the curriculum namely: Mathematics, Portuguese, History, Geography etc. Disciplines such as Pedagogy and Methodology, composing the set of professional knowledge, they have their place in the institution's curriculum, allowing us to conclude that there are two distinct natures, in terms of teacher training, one of general culture and one of professional training.

Keywords: Normal School. Teacher training. School Culture. Professional knowledge.

\section{Resumen}

En 1919, se solicitó al gobernador de Bahía autorización para operar la Escola Normal Nossa Senhora da Piedade, en la ciudad de Ilhéus, en la región sur de Bahía, comenzó 
a formar maestros de primaria. La investigación de los aportes de esta institución es significativa porque es un período en el que, se invirtieron en el proceso de internalización de instituciones que ofrecieran suficiente mano de obra para la difusión de la educación primaria. Este hecho se observó no solo en el estado de Bahía, sino en todo Brasil. En este artículo pregunta específicamente sobre los conocimientos que se ofrecen en la escuela normal de la institución, de inspiración francesa. Los resultados presentados cubren un período de tiempo de 1919 a 1925, cuya fecha inicial toma en cuenta el año em que se otorgó la autorización para esta institución escolar operar, y la fecha final corresponde al límite de reporte de registros del Jornal Correio de Ilhéos entre los años 1920 a 1925. A partir de un enfoque teórico con los autores de la historia cultural y con los autores que hablan de la organización del conocimiento de entrenamiento, se pudo resaltar elementos de la cultura escolar, organización y currículo de esta institución, que ofreció disciplinas de carácter pedagógico, a lo largo de la formación. Este hallazgo se destaca, en tiempos de predominio de asignaturas generales, "científicas" en los planes de estudio de las escuelas normales en Brasil, relegando las asignaturas pedagógicas al último año de formación. Las disciplinas "científicas", sin embargo, continuaron teniendo primacía en el currículo, a saber: Matemáticas, portugués, historia, geografía, etc. Disciplinas como la Pedagogía y la Metodología, que comprenden el conjunto de conocimientos profesionales, tienen su Iugar en el plan de estudios de la institución, lo que permite concluir sobre la existencia de dos naturalezas distintas, en cuanto a la formación del professorado, uno de cultura general y uno de formación profesional.

Palabras clave: Escuela normal. Formación de profesores. Cultura escolar Conocimientos profesionales.

\section{Introdução}

A temática formação de professores é historicamente debatida, sobretudo em função das muitas alterações que têm em vista obter a melhor configuração para a preparação dos sujeitos que a ela são confiados: “[...] foi no tempo das escolas normais, desde o século XIX, com a definição das qualidades que um professor devia possuir. Depois, no tempo da Escola Nova, a questão das características necessárias ao 'bom professor' voltou a ser matricial [...]” (NÓVOA, 2017, p. 1118). Essas alterações, muitas vezes cercadas de contradições, sempre giram em torno da definição dos melhores saberes para formar os futuros professores e assim repercutir no sistema escolar.

Entretanto, uma teia complexa de relações precisa ser levada em conta para melhor compreender o todo, a qual pode ser composta pelos: saberes 
disponibilizados, assim como os lugares de formação, os níveis de escolarização (primário, secundário, superior), as experiências de seus mestres e diversos outros fatores, os quais são marcados por aspectos sociais, históricos, culturais e políticos (HOFSTETTER; SCHNEUWLY, 2009).

Neste artigo consideramos a formação ofertada às normalistas da Escola Normal Nossa Senhora da Piedade, ao longo da década de 19201. A investigação das contribuições dessa instituição é significativa, pois se trata de um período no qual, a duras penas, se investia no processo de interiorização de instituições que oferecessem mão-de-obra suficiente para a propagação do ensino primário, não apenas no estado da Bahia, como em todo o Brasil. A propagação desse nível de ensino vinha sendo reclamada como uma necessidade urgente para a formação dos cidadãos, pois era indicativo de uma nação comprometida com marcos civilizatórios, a saber, a educação do seu povo (SOUZA, 2009).

Especificamente, nos interrogamos a respeito da formação ofertada na Escola Normal da Piedade. Os resultados apresentados advêm da análise de reportagens do Jornal Correio de Ilhéos (referente aos anos de 1920 a 1925), que nos possibilitaram compreender alguns aspectos da formação dos professores primários, bem como do apoio em uma bibliografia que nos auxiliaram a compreender práticas vivenciadas no interior dessa instituição.

A partir de uma aproximação teórica com autores da História Cultural, pretendemos compreender as práticas produzidas no cotidiano escolar, entendendo que essas não objetivam apenas cumprir aquilo que está prescrito nas normas, mas também contribuem para futuras reelaborações dessas normas, buscando atender às necessidades que surgem no dia a dia das escolas, e também àquelas que emergem das relações sociais, econômicas e culturais, e suscitam mudanças na cultura escolar. Em particular, consideramos os aportes teóricos de Dominique Julia (2001) e Michel de Certeau (2008). Esses autores nos alertam quanto à necessidade de reconhecer e identificar as singularidades que se evidenciam no cotidiano escolar e os desvios que

\footnotetext{
${ }^{1}$ Desde a sua instituição até os dias atuais essa instituição está localizada na cidade de Ilhéus, na região sul da Bahia. A escolha do lugar para a realização desta pesquisa decorre da participação das autoras em um projeto mais amplo, que tem como objetivo pesquisar historicamente a formação de professores que ensinam matemática, nos diversos níveis de ensino, na Bahia. Este artigo também faz parte dos resultados de pesquisa de pósdoutorado da primeira autora, supervisionado pela segunda.
} 
existem entre os dispositivos ou as normas que regulam as ações e aquilo que é efetivamente posto em prática. Também consideramos que no centro da formação de professores, ou de qualquer instituição formativa, estão os saberes, como afirmam Hofstetter e Schneuwly (2009) e neste trabalho buscamos evidenciar indícios da organização dos saberes da formação do professor primário da Escola Normal da Piedade.

\section{O lugar da pesquisa}

As primeiras décadas do século XX foram marcadas pela tentativa de expandir a oferta do ensino primário no país, respondendo a uma bandeira do movimento republicano o qual via na educação pública as bases para a formação do cidadão. Entretanto, essa aspiração se viria cumprir muito arduamente (SOUZA, 2009).

Com a demanda pela escolarização do povo, impôs-se também a necessidade de formar os agentes responsáveis por essa escolarização, a saber, os professores primários (NÓVOA, 1999). Essa demanda também não se cumpria com a celeridade desejada, entretanto, a preocupação com o perfil e saberes mínimos para selecionar o professor do ensino primário já eram requeridos, assim que o Estado passou a se obrigar com as questões da educação do povo. Tanuri (2000) chega a afirmar que "Antes porém que se fundassem as primeiras instituições destinadas a formar professores para as escolas primárias, já existiam preocupações no sentido de selecioná-los" (TANURI, 2000, p. 62).

A difusão de escolas de formação de professores no estado da Bahia se deu muito lentamente, ainda que a data de fundação da primeira instituição no estado, na cidade de Salvador, não ficou muito atrás das escolas normais das principais capitais do Brasil, tendo sido criada em 1836 (LIMA, 2006), um ano após a criação da primeira Escola Normal do Brasil, na província do Rio de Janeiro, em 1835 (TANURI, 2000).

Tendo em conta as dificuldades para se instituir espaços de formação de professores, um levantamento dos estudos realizados sobre essa temática, em relação ao contexto baiano, aponta a existência de um movimento de interiorização, que visava à expansão de instituições de formação de professores primários, para o interior do estado, encampado para atender à demanda pelo fornecimento de mão de obra para a atuação nas escolas primárias (NERY; GOMES; SILVA; 2019). 
A Escola Normal Nossa Senhora da Piedade, nasce, portanto, no contexto de interiorização de escolas de formação de professores. Entretanto, sua natureza privada, de caráter confessional, atendia também a outras finalidades, tais como educar as jovens da sociedade. A existência desse instituto alimentava as aspirações de famílias abastadas da cidade, que não necessitariam mais enviar as suas filhas para a capital, a fim de realizarem a formação de normalistas (NOGUEIRA, 2016, p. 93).

A Escola Normal da Piedade iniciou suas atividades em sete de fevereiro de 1916, quando a Madre Thaís do Sagrado Coração Paillart atendeu à solicitação do primeiro bispo que chegara a cidade de Ilhéus, Dom Manuel Paiva. O bispo havia solicitado à Madre Thaís, Provincial das Ursulinas do Brasil, a abertura de um colégio para “dar uma educação às jovens de sua diocese” (NOBRE, 1966, p. 7-8).

Madre Thaís, ursulina francesa da Comunidade de Quimperlé, em Bretanha França, aceitou a proposta para fundar o novo colégio. Em 21 de janeiro do ano seguinte, tendo "obtidas todas as autorizações de Roma", desembarcam em Ilhéus "três Madres e duas Irmãs dos conventos Nossa Senhora das Mercês e Nossa Senhora da Soledade designadas para a fundação" da nova casa ursulina (NOBRE, 1966, p. 8).

Considerando os princípios pedagógicos tradicionais da Ordem Ursulina, as atividades tiveram início na antiga residência episcopal. As Madres fundadoras se declararam cientes da importância da instituição para a cidade e para a região, que naquele momento se beneficiavam da rica cultura de cacau (NOBRE, 1966).

As escolas da Ordem Ursulina foram estabelecidas na França em 1641, essa Ordem foi considerada a "[...] comunidade de ensino feminino mais importante do Antigo Regime" 2 (CHAPRON, 2012, p. 34, tradução nossa), por que contribuiu fortemente para a oferta de instrução feminina de classes populares (CHAPRON, 2012).

Segundo Chapron (2012), essa instituição também participou do desenvolvimento do método simultâneo, muito comum, no período de organização de uma instrução popular, que se desenhava no século XVIII, e visava atender a uma demanda das classes escolares que eram marcadas pela superlotação "o método simultâneo foi rapidamente imposto como o único praticável’3 (p. 36, tradução nossa).

\footnotetext{
2 “[...] la communauté enseignante féminine la plus importante de l'Ancien Régime [...]”.

3 “[...] la méthode simultanée se soit rapidement imposée comme la seule praticable".
} 
Em acordo com a Ordem das Ursulinas, a Escola Normal da Piedade, em Ilhéus, também era de natureza confessional. Além do mais, tratava-se de uma instituição privada, que acompanhava um processo de disseminação da formação profissional técnica de professoras, demanda já reconhecida no país, e, com certeza, resultante da influência da cultura francesa, na qual estava inserida a fundadora da instituição.

Alguns anos após a inauguração da instituição, houve a ampliação das instalações e a construção de uma capela para servir de paróquia aos habitantes do Alto das Quintas ${ }^{4}$, na década de 1940, conforme pode ser visto na Figura 1.

No trigésimo aniversário de fundação da Escola Normal Nossa Senhora da Piedade a instituição havia ampliado suas atividades. Tendo iniciado apenas com o curso primário, funcionava com turmas do curso ginasial, autorizado pelo Decreto Ministerial, no.18.999, de 26 de junho de 1945, e com alunas da Escola Normal Nossa Senhora da Piedade. Também estava em funcionamento a Escola Profissional e Doméstica Dom Eduardo e a Escola Santa Ângela, uma escola com ensino primário gratuito destinado às crianças da comunidade do Alto da Vitória, que juntamente com o Orfanato Dom Eduardo formavam um conjunto que passou a ser denominado Instituto Nossa Senhora da Piedade.

Figura 1 - A igreja em estilo neo-gótico e as instalações da Escola Normal.

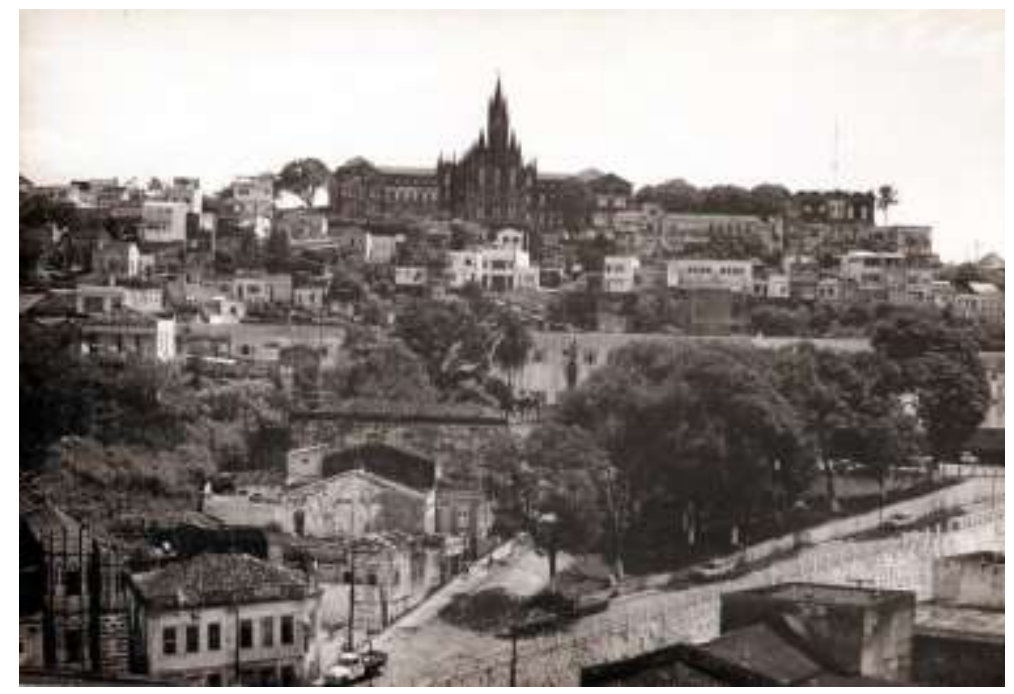

Fonte: Acervo do Museu do Instituto Nossa Senhora da Piedade.

\footnotetext{
${ }^{4}$ Construída em estilo neo-gótico, a capela está localizada na região que era conhecida como Alto das Quintas e pode ser visualizada de vários pontos da cidade.
} 
Neste ponto é importante destacar que o Instituto N. S. da Piedade gozava de muito prestígio na sociedade, as principais atividades da instituição eram anunciadas nos jornais, como: matrícula, festa de formatura, resultados de exames de admissão, resultados de exames escolares etc. De modo que muitos elementos da estrutura da escola puderam ser apreendidos a partir da leitura de jornais da época, em especial, o Correio de Ilhéos $^{5}$. A instituição sempre convidava a imprensa para participar de seus eventos (Figura 2) e contava também com a presença ilustre de juízes e bispos (Figura 3).

Figura 2 - Cerimônia no salão de Conferências

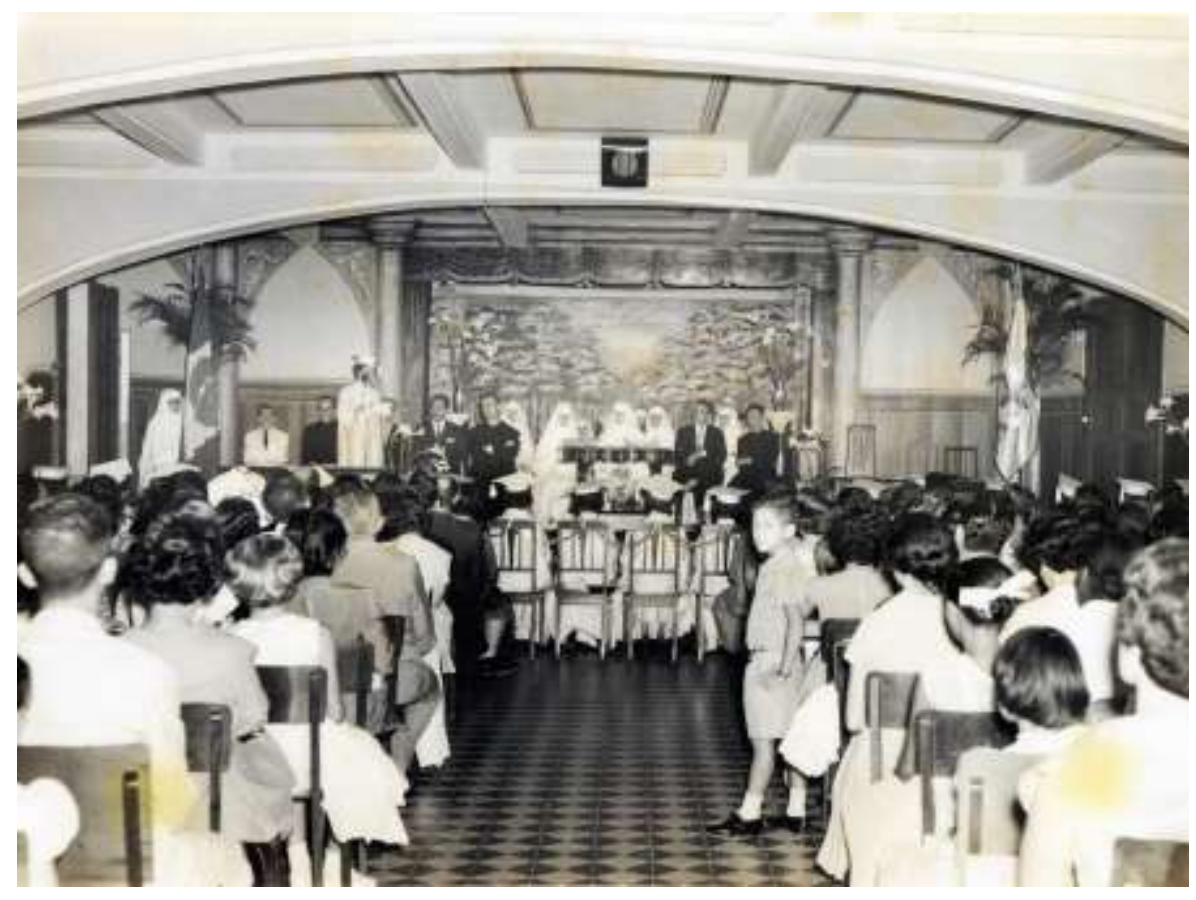

Fonte: Acervo do Museu do Instituto Nossa Senhora da Piedade.

A instituição também usava o espaço cedido no jornal da cidade para a publicação de informes como a data de início das atividades escolares e até a publicação dos resultados obtidos pelas normalistas nas diferentes disciplinas (CORREIO DE ILHÉUS, 1924, ANO VI, N. 399, JAN, BA).

\footnotetext{
${ }^{5}$ Essa documentação se encontra disponível no Centro de Documentação da Universidade Estadual de Santa Cruz - Ilhéus, Bahia.
} 
Figura 3 - Alunas normalistas com Madre Thaís e o Bispo D. Eduardo.

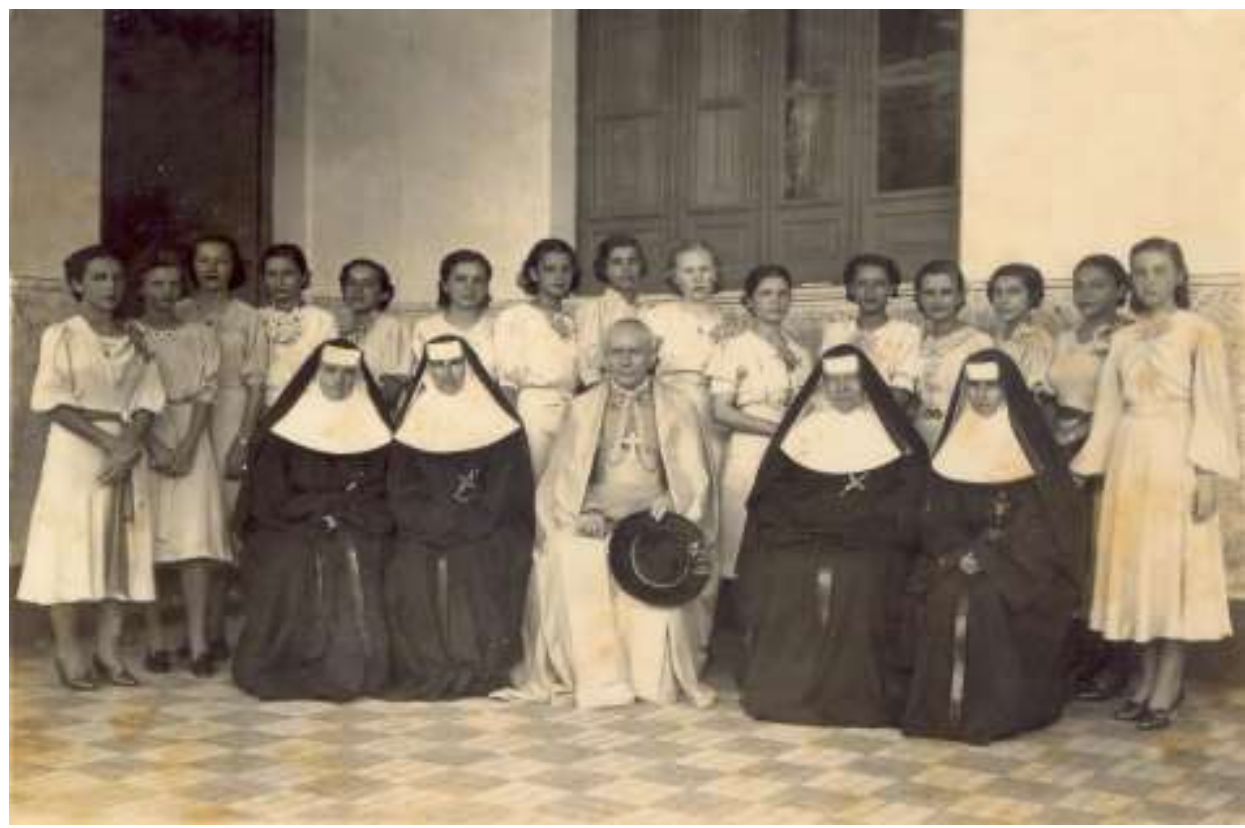

Fonte: Acervo do Museu do Instituto Nossa Senhora da Piedade.

Devido à sua importância e prestígio, em três de fevereiro de 1922 a Escola Normal do Instituto N. S. da Piedade foi equiparada à Escola Normal do Estado, pelo Decreto n. 2.766. Essa equiparação foi muito importante, pois possibilitava à instituição "[...] gozar de todos os direitos e prerrogativas" concedidas às escolas oficiais (CORREIO DE ILHÉOS, 1922).

A importância da instituição também fora ressaltada no relatório do delegado da Instrução Pública da região, o qual se queixara da falta de apoio do estado, ainda que o munícipio de Ilhéus fosse um dos que mais contribuísse com esse, oportunidade na qual ressaltou a importância da Escola Normal das Ursulinas, que a duras penas auxiliava para a melhoria do quadro da educação na cidade (CORREIO DE ILHÉUS, 1923, ANO III, N. 241, JAN, BA).

A equiparação da Escola da Piedade trouxe vantagens em termos de reconhecimento e autoridade, entretanto a colocou sob a custódia do Estado, ainda que esse não fosse o responsável pelo seu financiamento. A escola deveria responder ao governo e uma das formas de se obter esse controle se dava pela instituição de um fiscal. No ano de 1924, por exemplo, o jornal Correio de Ilhéos anunciou a escolha do novo fiscal da Escola, o professor Américo Guimarães Costa. 


\section{Vestígios dos saberes de cultura geral e profissional no currículo da Escola Normal N. S. da Piedade}

No início de 1920, Madre Thaís recebeu um inspetor para conduzir o exame de admissão das alunas candidatas à Escola Normal Nossa Senhora da Piedade, a instituição havia sido autorizada no final de 1919. O primeiro exame de admissão à Escola Normal ocorreu com uma banca composta pelos seguintes professores: Dr. Camilo Castelo Branco, Dr. Honorato Maltez, Padre Severino Leite Ramalho, Madre Maria Teresa do Menino Jesus Decroocq e Madre Marie du Sacré-coeur Perrien (CORREIO DE ILHÉOS, 1922). Ao longo da década de 1920, a realização dos exames de admissão se dava sempre perante uma banca avaliadora, formada por cinco professores. No ano de 1925 esse exame foi realizado, inclusive, na presença do fiscal do governo (CORREIO DE ILHÉUS, 1925, ANO V, N. 568, MAR, BA).

As escolas específicas para a formação do professor primário ainda estavam em fase de implantação, tal realidade, portanto, também refletia no corpo docente das instituições. A esse tempo, a Pedagogia, como conhecimento disciplinar, acadêmico, estava em fase de sistematização, era corrente no período e o é muito fortemente ainda hoje, a concepção de que os conhecimentos necessários para ensinar eram apenas os conhecimentos do conteúdo. Disciplinas como Pedagogia, Psicologia, Didática constituíam, muito timidamente, os resultados de um movimento de conquista da educação como ciência. Portanto, as autoridades educacionais emergiam de meios como os da saúde, do direito, pessoas consideradas de notório saber.

O jornal Correio de Ilhéus (1922, ANO II, N. 175, AGO, BA) retrata bem esse fato ao anunciar que dois professores, Ignácio de Menezes e Durval Gama, renunciaram a cadeiras que ocupavam na Escola Normal da Bahia para serem nomeados na Faculdade de Medicina. Tal notícia dá indícios de que se tratava de pessoas não ligadas à educação, sobretudo, não ligados à formação de professores primários, pelo contrário, eram docentes pertencentes ao campo da saúde, mas que atuavam formando professores na Escola Normal, provavelmente, a julgar pelo "notório saber" que demonstravam. 
É importante destacar também que, nesse contexto de evolução da educação, como um conhecimento científico, acadêmico e disciplinar, o primeiro fiscal destinado à supervisão da Escola Normal da Piedade foi o farmacêutico Joaquim Lopes Filho. Apenas dois anos depois ele foi substituído por professores (CORREIO DE ILHÉOS, 1924, n. 447). Uma das substitutas foi a professora Amélia, sobre a qual ressaltou-se sua competência pelo fato de ter sido professora da escola municipal, tendo mais de 12 anos de experiência, conhecimentos em "matéria de ensino e instrução", por ter sido aluna da Escola Normal da Bahia e pela sua assiduidade na cadeira na qual trabalhava (CORREIO DE ILHÉUS, 1925, ANO V, N. 554, FEV, BA). Tal discriminação é importante, diante de um cenário no qual a especificidade do trabalho pedagógico, bem como dos aspectos da profissionalização dos professores e de sua formação profissional serem pouco ou nada reconhecidos.

Os anos de 1920 foram marcados por uma série de preocupações com respeito à instrução pública, tão evidente que várias reformas educacionais foram desencadeadas ao longo dessa década, nos diferentes estados do país (CARVALHO, 2000). Com relação à formação dos professores, disputava-se (disputa ainda presente nos dias atuais) no interior dessa, culturas de naturezas diferentes: a cultura geral, que diz respeito à oferta de uma formação mais centrada em saberes a ensinar ${ }^{6}$, organizados em disciplinas como Matemática, Língua Portuguesa, Geografia etc., e a cultura profissional, representada, sobretudo, por disciplinas como Pedagogia, Metodologia, Psicologia etc. Segundo Lussi Borer, essa situação também resultava de outra característica:

Constata-se assim que o modelo superior é mais favorável ao desenvolvimento de saberes para ensinar7, no seio da formação de professores, o modelo normal se encontra em tensão entre a missão de garantir a melhor formação geral possível e sua vocação profissional" (LUSSI BORER, 2009, p. 45, tradução nossa) ${ }^{8}$.

\footnotetext{
${ }^{6}$ Entende-se por saberes a ensinar o objeto do ensino do futuro professor em termos de Aritmética, Português, Geografia, História etc., que o professor precisa ensinar aos seus alunos (HOFSTETTER; SCHNEUWLY, 2009).

${ }^{7}$ Denomina-se saberes para ensinar os que são mobilizados no trabalho do professor ao ministrar um conteúdo, ou no processo educativo em geral, tais como: Psicologia da Educação, História da Educação, Metodologia do Ensino de Aritmética, Pedagogia, Didática Especial e tantos outros (HOFSTETTER; SCHNEUWLY, 2009).

8 "On constate ainsi que le modèle supérieur est plus favorable au dévelopment de savoirs pour enseigner au sein des formations à l'enseignement, le modèle normal se trouvant en
} 
O movimento observado por Lussi Borer, no contexto Suíço, tem paralelos na França (LUSSI BORER, 2009), como também no Brasil, quando Silva e Valente (2019) observam a estrutura dos institutos de educação do Rio de Janeiro e São Paulo (década de 1930), instituições que materializaram a primeira formação de professores de nível superior, realizada estritamente com conteúdos de caráter profissional, em detrimento daqueles de formação geral (SILVA; VALENTE, 2019).

Ao longo de muitos anos a formação de professores na escola normal foi marcada pela subdivisão entre uma formação mais geral e uma formação pedagógica. Essa realidade não foi uma característica apenas do Brasil, em período muito similar, a formação de professores nos países ocidentais vivenciava o mesmo dilema. $\mathrm{Na}$ formação de professores no nível secundário, predominava o ensino de disciplinas de Matemática, Língua Portuguesa, Ciências etc., juntamente com disciplinas do corpo de conhecimentos que se organizava em torno da criação de uma ciência da educação: psicologia, didática e a própria Pedagogia (HOFSTETTER; SCHNEUWLY, 2009; VALENTE; SILVA, 2019).

No primeiro ano, as normalistas da Escola Normal do Instituto N. S. da Piedade tinham disciplinas como Português; Geografia; Aritmética; Pedagogia; Ginástica; Costura; no segundo ano Francês; História Universal; Português, "Mathematicas", Pedagogia e Metodologia, Costura e Chorografia; no terceiro ano História natural, História do Brasil, Costura, Português, Gráfica de desenho, "Mathematicas", Pedagogia e Metodologia, Física e Química, Música; no quarto ano Pedagogia; Economia Doméstica; Metodologia; Ciências Naturais; Economia Política Instrução Moral e Cívica; Higiene, Antropologia e Psicologia Experimental; Música (CORREIO DE ILHÉOS, 1922; 1924; 1925). Essas disciplinas eram avaliadas com o emprego de exames orais e escritos, especialmente para Português, Mathematicas, Pedagogia e Methodologia, cujos resultados costumavam ser publicados no jornal, juntamente com as designações para cada aluna: distintamente, plenamente e simplesmente.

É significativo salientar que na Escola Normal da Piedade a disciplina de Pedagogia era ofertada desde o primeiro ano de formação. Nesse mesmo ano, as 
normalistas estudavam outras disciplinas de caráter geral. Pedagogia era a única disciplina de cunho profissional no primeiro ano de formação das normalistas, mas a sua inclusão pode ser reveladora de um modo de conceber a formação, para além da aprendizagem dos conteúdos das disciplinas de cultura geral.

A partir do segundo ano de formação, as normalistas se deparavam com a disciplina Pedagogia e Metodologia. Não se tem muitos documentos que ajudem a elucidar a natureza da Pedagogia ofertada no segundo ano, o que não nos impede de levantar como hipótese que essa disciplina se aproximasse agora de um caráter menos teórico das doutrinas pedagógicas, e passasse a considerar, como a própria nomenclatura advoga, aspectos metodológicos relativos à profissão.

A carga de disciplinas de cultura geral, ao longo de toda a formação da Escola Normal, ainda era superior à das disciplinas de cultura profissional. Essa configuração se mantinha, ainda que se estivesse estabelecido como pré-requisito para o ingresso na formação de professores da Piedade a apresentação da certidão de aprovação no exame de admissão, além da aprovação nos exames finais do Curso Complementar — também se estabelecia como critério que as candidatas tivessem, ao menos, dezesseis anos.

A exigência da comprovação da realização do Curso Complementar respondia a uma preocupação existente com relação à formação geral básica dos futuros professores. O Curso Complementar, como o próprio nome indica, deveria reforçar, complementar o domínio de conhecimentos gerais, como Aritmética, Língua Portuguesa, Francês, Geografia etc. (TANURI, 2000; VALENTE, 2011).

O Curso Complementar realizado poderia ser de qualquer escola pública (CORREIO DE ILHÉOS, 1921, CORREIO DE ILHÉUS, 1924, ANO VI, N. 400, JAN, BA). A matrícula no Curso Complementar, por sua vez, tinha como prérequisitos que os candidatos tivessem sido aprovados nos exames finais do Ensino Primário e que tivessem idade entre doze e dezesseis anos (Correio de Ilhéus, 1923, Ano III, n. 253, fev, BA). O Curso Complementar não possuía nenhum caráter profissionalizante e servia, ao contrário, para complementar a formação geral, iniciada nos estudos realizados na Escola Primária.

Entretanto, no período investigado, a oferta da formação no Curso Complementar sofreu muitos problemas. Em 1922 há uma seleção para a Cadeira 
Complementar, na qual todos os candidatos foram reprovados (CORREIO DE ILHÉUS, 1922, ANO II, N. 173, JUL, BA). Em 1923, lê-se no jornal: "Está Aceffala a escola complementar". A nota trata da ausência do diretor da escola, que estava na capital e continuava recebendo seus proventos (CORREIO DE ILHÉUS, 1923, ANO III, N. 373, NOV, BA). O problema persistiu ainda em 1924, com a indicação de que a "cadeira complementar" foi considerada vaga (CORREIO DE ILHÉUS, 1924, ANO VI, N. 445, MAI, BA).

\section{Considerações finais}

Pode-se concluir, portanto, que a formação das normalistas estava concentrada na oferta de disciplinas do grupo de formação geral: "Mathematicas" (as quais compreendiam Aritmética, Álgebra e Geometria), Língua Portuguesa, Geografia, História etc. Faz-se necessário, entretanto, a análise de documentações que apontem para a compreensão de que tipo de abordagem se fazia desse primeiro grupo de matérias, por exemplo: que concepção de "Mathematicas" se advogava para a formação das normalistas, uma matemática que partisse dos seus elementares, a generalização dos quais culminasse em uma matemática superior, a saber a Álgebra? Ou se pretendia uma matemática mais próxima dos saberes a ensinar na Escola Primária? E o mesmo movimento com as demais disciplinas de caráter geral, para compreender se e/ou como elas dialogavam com disciplinas de natureza pedagógica.

De outro modo, a oferta das disciplinas Pedagogia e Metodologia, bem como Metodologia Prática, nos permite conjecturar a existência de uma abordagem de saberes que pretendia uma aproximação com os problemas metodológicos do ensino, de como ensinar as matérias do Ensino Primário. Referimo-nos à parte da formação dedicada aos métodos, procedimentos para o ensino de matemática, português, história etc., dito de outro modo, os saberes para ensinar as diferentes matérias.

O confronto com documentações de outra natureza permitiu ir além e melhor caracterizar as "maneiras de fazer" dos professores, conforme sugere Certeau (2008), investigando como a escola respondeu ao sistema de controle do governo e sua relação com o fiscal destinado para fins de supervisionar o processo de formação das normalistas. 
Por ora, é possível concluir quanto à existência de duas culturas que influenciavam a formação das professoras primárias da Piedade: uma devedora de saberes disciplinares: Mathemáticas, Português, Geografia etc.; de outro lado, a previsão de uma cultura pedagógica, que em comparação com outras realidades do país, na mesma época (SILVA; VALENTE, 2019) distribuía, ao longo de toda a formação, não apenas nos últimos anos, as disciplinas de Pedagogia e Metodologia, saberes profissionais.

\section{Referências}

CARVAlHO, M. M. C. Modernidade Pedagógica e Modelos de Formação Docente. São Paulo em Perspectiva, São Paulo, v. 14, n. 1, jan./mar. 2000. Disponível em: http://www.scielo.br/scielo.php?script=sci_arttext\&pid=S0102-88392000000100013. Acesso em: 13 maio 2014.

CERTEAU, M. A Invenção do Cotidiano: 1. Artes de Fazer. Trad. Ephraim Ferreira Alves. 15. ed. Rio de Janeiro: Vozes, 2008.

CHAPRON, E. Écoles charitables et économie du livre au XVIIIe siècle: les livres à l'usage des élèves des ursulines. Revue d'bistoire moderne \& Contemporaine, Belin, n. 59-4, p. 33-50, 2012.

HOFSTETTER, R.; SCHNEUWLY, B. Introduction. Savoirs en (trans)formation. Au coeur des professions de l'enseignement et de la formation. In : HOFSTETTER, R.; SCHNEUWLY, B. Savoirs en (trans) formation: ao coeur des professions de l'enseignement et de la formation. Bruxelles: Raisons éducatives, 2009. p. 7-40.

JULIA, D. A cultura escolar como objeto histórico. Revista Brasileira de História da Educação, Campinas, n. 1.p. 9-45, jan./jun. 2001.

LIMA, M. M. L. Ingressos das mulheres no magistério da Babia: o resgate de uma história. 2006. 181. Tese (Doutorado em Educação) — Faculdade de Educação, Universidade Federal da Bahia, Salvador, 2006. Disponível em: http://www.repositorio.ufba.br/ri/handle/ri/11082. Acesso em: 25 out. 2018.

LUSSI BORER, V. Les savoirs : un enjeu crucial de l'institutionnalisation des formations à l'enseignement. In: HOFSTETTER, R. ; SCHNEUWLY, B. Savoirs en (trans) formation: ao coeur des professions de l'enseignement et de la formation. Bruxelles : Raisons éducatives, 2009. p. 41-58.

NERY, W. F.; GOMES, L. P. S.; SILVA, M. R. I. S. Formação de professores nas escolas normais da Bahia: uma leitura de histórias a respeito da cultura escolar e dos saberes matemáticos. VIDYA (SANTA MARIA. ONLINE), v. 39, p. 415-428, 2019. https://doi.org/10.37781/vidya.v39i2.2852.

NOBRE, P. A. Madre Thaís e o Instituto Nossa Senhora da Piedade. Ilhéus: Imprimatur, 1966. 
NOGUEIRA, R. A. História e Memórias do Instituto Nossa Senhora da Piedade: 100 anos de existência 1916-2016. Ilhéus: Editus, 2016.

NÓVOA, A. O passado e o presente dos professores. In: NÓVOA, A. Profissão professor. 2 ed. Porto: Porto Editora, 1999. p. 31-34.

NÓVOA, A. Firmar a posição como professor, afirmar a profissão docente. Cad. Pesqui., São Paulo, v. 47, n. 166, p. 1106-1133, 2017. Disponível em: http://www.scielo.br/scielo.php?script=sci_arttext\&pid=S0100-15742017000401106\&lng=pt\&nrm=iso. Acesso em: 05 out. 2020. https://doi.org/10.1590/198053144843.

SILVA, M. R. I. S. S.; VALENTE, W. R. Aritméticas? A produção de uma aritmética profissional da formação do professor dos anos iniciais. Revista Cocar, Edição Especial, n. 6, p. 136-156, mai./ago. 2019. Disponível em: https://paginas.uepa.br/seer/index.php/cocar/index/ Acesso em: 09 jul. 2019.

SOUZA, R. F. Alicerces da Pátria: História da Escola Primária no Estado de São Paulo (1890 - 1976). Campinas: Mercado de Letras, 2009.

TANURI, M. L. História da Formação de Professores. Revista Brasileira de Educação, São Paulo, n. 14, p. 61-88, mai./jun./ago. 2000.

VALENTE, W. R. A Matemática na Formação do Professor do Ensino Primário: São Paulo, 18751930. São Paulo: Annablume; Fapesp, 2011.

Correio de Ilhéus, 1922, Ano II, n. 173, jul, BA.

Correio de Ilbéus, 1922, Ano II, n. 214, nov, BA.

Correio de Ilhéus, 1922, Ano II, n. 222, nov, BA.

Correio de Ilhéus, 1923, Ano III, n. 241, jan, BA.

Correio de Ilhéus, 1923, Ano III, n. 253, fev, BA.

Correio de Ilhéus, 1923, Ano III, n. 373, nov, BA.

Correio de Ilhéus, 1924, Ano VI, n. 399, jan, BA.

Correio de Ilhéus, 1924, Ano VI, n. 445, mai, BA.

Correio de Ilbéus, 1924, Ano VI, n. 518, nov, BA.

Correio de Ilhéus, 1925, Ano V, n. 554, fev, BA.

Correio de Ilhéus, 1925, Ano V, n. 568, mar, BA. 
EQUIPARAÇÃO DO COLLÉGIO PIEDADE Á ESCOLA NORMAL. Correio de Ilhéos, 1922, Ano II, n. 105, fev, BA.

EXAMES CURSO COMPLEMENTAR. Correio de Ilhéos, 1921, Ano I, n. 48, nov, BA.

EXAMES. Correio de ilhéos, 1922, ANO II, N. 214, NOV, BA.

EXAMES. Correio de ilhéos, 1924, ANO VI, N. 419, MAR, BA.

EXAMES. Correio de ilhéos, 1925, ANO V, N. 677, NOV, BA.

RECEBIDO: $31 / 08 / 2020$

APROVADO: 06/10/2020

RECEIVED: 08/31/2020

APPROVED: $10 / 06 / 2020$

RECIBIDO: $31 / 08 / 2020$

APROBADO: 06/10/2020 